\title{
A Comparative Study of a 1/4-scale Gulfstream G550 Aircraft Nose Gear Model
}

\author{
Nikolas S. Zawodny, ${ }^{1}$ Fei Liu, ${ }^{2}$ Tarik Yardibi, ${ }^{3}$ Louis Cattafesta ${ }^{4}$ \\ Florida Center for Advanced Aero-Propulsion \\ Interdisciplinary Microsystems Group \\ University of Florida, Gainesville, FL 32611 \\ Mehdi R. Khorrami, ${ }^{5}$ Dan H. Neuhart ${ }^{6}$ \\ NASA Langley Research Center \\ Hampton, VA 23681 \\ Thomas Van de Ven ${ }^{7}$ \\ Gulfstream Aerospace Corporation \\ Savannah, GA 31407
}

\begin{abstract}
A series of fluid dynamic and aeroacoustic wind tunnel experiments are performed at the University of Florida Aeroacoustic Flow Facility and the NASA-Langley Basic Aerodynamic Research Tunnel Facility on a high-fidelity 1/4-scale model of Gulfstream G550 aircraft nose gear. The primary objectives of this study are to obtain a comprehensive aeroacoustic dataset for a nose landing gear and to provide a clearer understanding of landing gear contributions to overall airframe noise of commercial aircraft during landing configurations. Data measurement and analysis consist of mean and fluctuating model surface pressure, noise source localization maps using a largeaperture microphone directional array, and the determination of far field noise level spectra using a linear array of free field microphones. A total of 24 test runs are performed, consisting of four model assembly configurations, each of which is subjected to three test section speeds, in two different test section orientations. The different model assembly configurations vary in complexity from a fully-dressed to a partially-dressed geometry. The two model orientations provide flyover and sideline views from the perspective of a phased acoustic array for noise source localization via beamforming. Results show that the torque arm section of the model exhibits the highest rms pressures for all model configurations, which is also evidenced in the sideline view noise source maps for the partially-dressed model geometries. Analysis of acoustic spectra data from the linear array microphones shows a slight decrease in sound pressure levels at mid to high frequencies for the partially-dressed cavity open model configuration. In addition, far field sound pressure level spectra scale approximately with the $6^{\text {th }}$ power of velocity and do not exhibit traditional Strouhal number scaling behavior.
\end{abstract}

\section{Introduction}

$I^{2}$ $\mathrm{N}$ recent years, landing gear have been identified as major components of airframe noise during approach and landing for commercial aircraft. They are the least studied and understood contributors of airframe noise, mostly due to complex flow patterns associated with intricate gear component geometries. Nose landing gear is of primary interest due to the fact that it has been shown to be a prominent noise source ${ }^{1}$ and is more amenable than the main landing gear to scaled wind tunnel testing. Previous studies have emphasized the importance of

\footnotetext{
${ }^{1}$ Graduate Research Assistant, MAE Department, P.O. Box 116250, Student Member AIAA

${ }^{2}$ Post-Doctoral Associate, MAE Department, P.O. Box 116250, Member AIAA

${ }^{3}$ Graduate Research Assistant, ECE Department, P.O. Box 116200, Student Member AIAA

${ }^{4}$ Professor, MAE Department, P.O. Box 116250, Associate Fellow AIAA, cattafes@ufl.edu

${ }^{5}$ Research Engineer, Computational AeroSciences Branch, MS 128, Associate Fellow AIAA

${ }^{6}$ Research Engineer, Flow Physics and Control Branch, MS 170

${ }^{7}$ Senior Acoustics Engineer, Acoustics \& Vibration Group, Member AIAA
} 
fine structural details present in the actual gear assembly, as these have been found to contribute to higher frequency noise. ${ }^{2,3}$ This implies that reduced-scale testing of such components must be done with high-fidelity models to ensure that accurate analysis of noise source contributions can be made over as broad a frequency range as possible.

One subject of great interest in the examination of landing gear noise has been the scaling of far field noise levels with flow speed. Past studies have shown that noise generation due to low Mach number flows over solid bodies typically scales with the $6^{\text {th }}$ power of velocity. ${ }^{1,3,4}$ This scaling has been shown to hold for landing gear at low- and mid-frequency ranges where the sources can be considered to be acoustically compact, exhibiting the radiation behavior of a dipole source. ${ }^{3}$ At high frequencies, however, the compactness of the sources diminishes as acoustic wavelength becomes comparable with the dimensions of the gear components. As the various gear components begin to act as reflective sources, the radiation efficiencies of the sources degrade from dipole- to "quadrupole-like" scaling with the $7^{\text {th }}$ power of velocity. ${ }^{3}$ An investigation of these trends is one of the topics addressed in this paper.

In addition to the scaling of the far field noise levels, localization of gear noise sources has become important in an attempt to implement acoustic treatments to mitigate them. Noise source localization is achieved through the process of beamforming via a planar acoustic array of multiple microphones, in which the focal point of the array is electronically steered through space to identify the spatial regions with dominant sound radiation. While numerous beamforming algorithms have been developed and implemented for aeroacoustic applications, most operate with the assumption that the sound sources under investigation can be modeled as a distribution of incoherent monopoles. Deviations from these assumptions limit the accuracy of the array estimates. ${ }^{5}$ The most common and simplest algorithm is the Delay-and-Sum (DAS) beamformer which, as the name implies, consists of the summation of delayed and weighted versions of each microphone signal. Through this process, source signals in spatial regions of interest are strengthened while signals from other regions are deemphasized. The major drawback to this standard method is poor resolution at lower frequencies and high sidelobe levels. Improvements to DAS include the Standard and Robust Capon beamformers (SCB and RCB respectively), which yield higher resolution and lower sidelobe levels via near-optimal suppression. ${ }^{6}$ Other more complex, but resource intensive algorithms such as the Deconvolution Approach for the Mapping of Acoustic Sources (DAMAS), ${ }^{7}$ Sparsity-Constrained DAMAS (SC-DAMAS) and Covariance Matrix Fitting (CMF), ${ }^{8}$ and CLEAN based on spatial coherence (CLEAN-SC $)^{9}$ have improved on the deficiencies of DAS. As a preliminary step, DAS and RCB algorithms are employed in this study.

The platform of the experiments is a high-fidelity 1/4-scale model of a Gulfstream G550 aircraft nose landing gear. This study spans two sets of experiments in the open-jet University of Florida Aeroacoustic Flow Facility (UFAFF). For the first entry, mean and fluctuating surface pressure data are acquired and compared with the comprehensive aerodynamic measurements acquired in NASA Langley's Basic Aerodynamic Research Tunnel (BART). ${ }^{10}$ This comparison serves to highlight any inherent differences that may exist between aerodynamic measurements obtained in an open-jet facility to those obtained in a conventional closed-wall tunnel. The second entry focuses on aeroacoustic measurements of "benchmark" model configurations, ranging from a fully-dressed model to a partially-dressed model, in order to determine the contribution of specific gear components to the far field sound. These experiments are part of an ongoing collaborative effort between NASA Langley Research Center, Gulfstream Aerospace Corporation, and the University of Florida to conduct detailed aeroacoustic measurements of a nose landing gear in order to gain a clearer understanding of the contributions of aircraft landing gear to overall airframe noise during aircraft approach and landing.

\section{Experimental Approach}

\section{A. Model Description and Instrumentation}

The model employed in the current study is a 1/4-scale high-fidelity replica of a Gulfstream G550 nose landing gear that includes part of the lower fuselage section and the gear cavity. A full description of the gear model is provided in reference 10. Only a brief summary of its critical features is given here. The primary components of the nose gear model are shown in Figure 1. The foundation of the model is a 3/8"-thick aluminum plate measuring 40 " wide by 58 " long $(1.016 \mathrm{~m}$ by $1.473 \mathrm{~m})$. The fuselage replica is a $1 / 8$ "-thick carbon fiber shell equipped with a removable panel for easy access to the gear cavity, through which pressure lines are routed out of the model. The primary hydraulic lines and electrical wirings are simulated using copper tubes of different diameters. The wheels are mounted to a metal axle and can be rotated independently and then locked at a series of discrete angles in $10^{\circ}$ increments. The starboard wheel contains a set of circumferentially-distributed pressure taps along the outer wheel surface spaced every $20^{\circ}$, while the port wheel is comprised of two rows of radially- 
distributed pressure taps. The more intricate components of the gear assembly, such as the steering mechanism and light cluster, are made of a polycarbonate material and secured about the main shaft of the model via small threaded screws. In Figure 1, the nose gear model is oriented in a ceiling arrangement where the gear plate is suspended from the upper rails of the UFAFF test section.
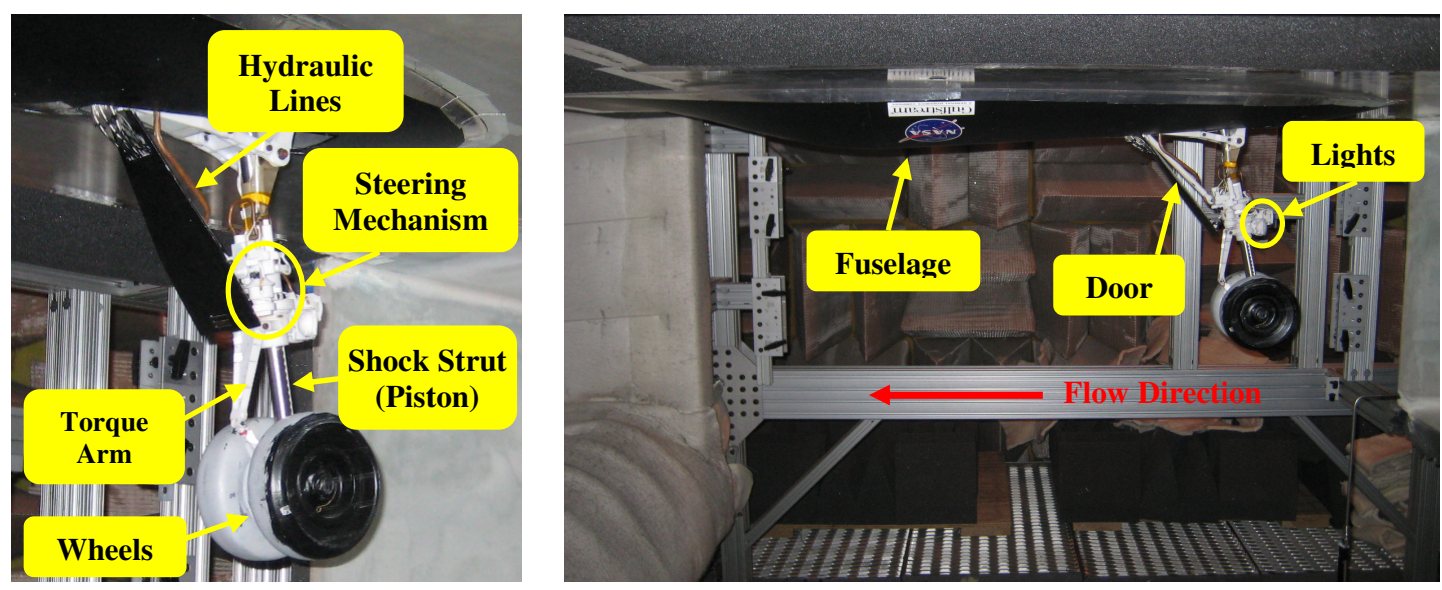

Figure 1. Primary components of fully-dressed nose gear model in the UFAFF shown during model installation. (Exposed reflective surfaces are acoustically treated during testing.)

There are 126 pressure taps for steady pressure measurements and 16 flush-mounted unsteady pressure transducers located strategically on the primary components of the gear. The unsteady pressure transducers on the nose gear are Model LQ-12-062-2D Kulites. The steady pressure lines and Kulite electrical and reference pressure lines are routed through the cavity of the model out of the test section. The ambient tunnel pressure is used as a reference pressure for all pressure transducers. The Kulite locations are summarized in Table 1. The Kulites are powered through a parallel-circuit "patch panel" using a $10 \mathrm{~V}$ dc power supply, yielding a rated pressure range of \pm 1.0 psi differential (PSID).

Table 1. Kulite channel locations on nose gear model.

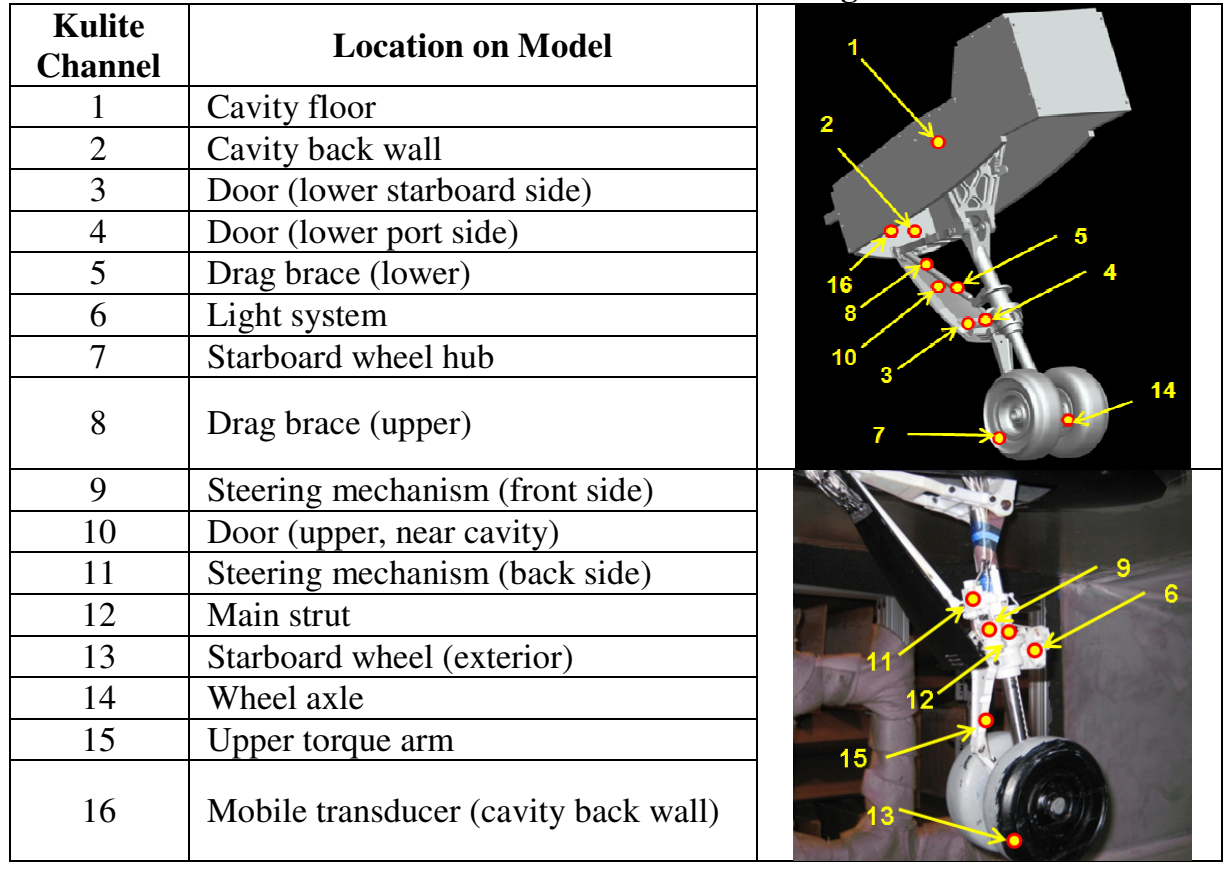




\section{B. Facilities}

The UFAFF is a low-noise, open-jet acoustic wind tunnel with a cross-section of 29 " high by 44 " wide by 72 " long $(0.737 \mathrm{~m}$ by $1.118 \mathrm{~m}$ by $1.83 \mathrm{~m}$ ) installed in an ISO $3745-$ certified $100 \mathrm{~Hz}$ anechoic chamber. The inner walls, floor, and ceiling of the aeroacoustic chamber are populated with 36 " $(0.914 \mathrm{~m})$-tall acoustic wedges. The floor of the test section is also populated with acoustic wedges measuring $11.75 "(0.298 \mathrm{~m})$ tall. The open-jet test section is bounded by an aluminum-frame test stand, within which aerodynamic models and acoustic foam sidewalls may be installed. The maximum empty test section velocity is approximately $75 \mathrm{~m} / \mathrm{s}$. The maximum safe tunnel velocity with the nose gear model installed is $66 \mathrm{~m} / \mathrm{s}$, corresponding to a Mach number of $M=0.189$. A schematic of the

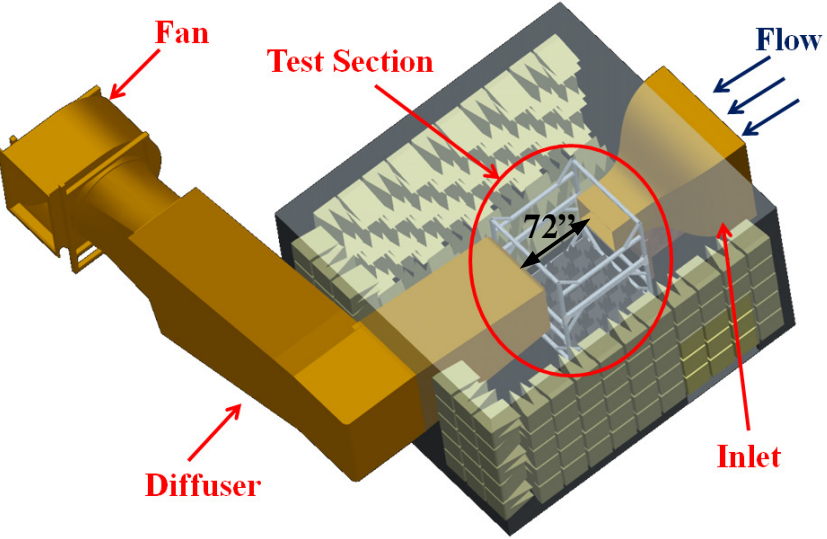

Figure 2. Schematic of the UFAFF. wind tunnel is shown in Figure 2.

Unlike the UFAFF, the BART Facility located at NASA-Langley is not an aeroacoustic facility but rather a conventional open-return wind tunnel with a rigid-wall test section used to investigate characteristics of complex flow fields and to validate computational fluid dynamics (CFD) methods. ${ }^{11}$ Its test section dimensions are 28 " by 40 " $(0.711 \mathrm{~m}$ by $1.016 \mathrm{~m})$ with a length of 120 " $(3.048 \mathrm{~m})$. The maximum flow velocity in the empty test section is approximately $67 \mathrm{~m} / \mathrm{s}$. The similar test section cross-sectional dimensions of the two flow facilities minimize installation issues that can occur with a trans-facility model, making them good candidates for collaborative experiments.

\section{Instrumentation and Data Acquisition}

\section{C.1 Atmospheric and Flow Properties}

Prior to each set of experiments, the atmospheric properties of the UFAFF are determined. With the nose gear model installed, the wind tunnel is run at the desired flow speeds, and ambient pressure, temperature, and relative humidity are measured. This atmospheric data is acquired by monitoring local weather conditions at a nearby building. Tunnel speed is measured using a deployable pitot static probe installed 6 inches $(0.152 \mathrm{~m})$ below the centerline of the wheels, and 12 inches $(0.305 \mathrm{~m})$ downstream of the inlet trailing edge (see Figure 3). This data, coupled with atmospheric data previously mentioned, allows the computation of a local isentropic speed of sound, and thus the Mach number.

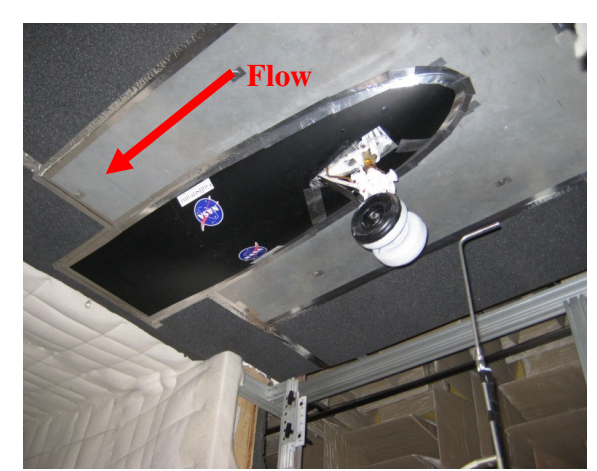

Figure 3. Installation of pitot static probe for flow speed measurements.

\section{C.2 Phased and Linear Arrays}

University of Florida's large aperture microphone directional array (LAMDA) is a phased acoustic array consisting of 90 Panasonic WM-61A electret microphones flush-mounted in a 1/4"-thick, 72" (1.829 m) diameter aluminum plate located 48 " $(1.22 \mathrm{~m})$ below the centerline of the test section. The microphones are oriented in two nested, logarithmic-spaced spiral patterns, which provide good sidelobe characteristics within the frequency range of interest (discussed later). ${ }^{12}$ The nested patterns consist of an inner array with 45 elements and an outer array with 63 elements. The two nested arrays share 18 microphones. Figure 4 shows the microphone locations of the LAMDA. For this study, data is collected using the outer LAMDA so as to allow beamforming with improved resolution at lower frequencies. For the outer array, there are nine total spiral arms, each of which contains 7 microphone elements with an outer array microphone diameter of 44 " $(1.118 \mathrm{~m})$. 


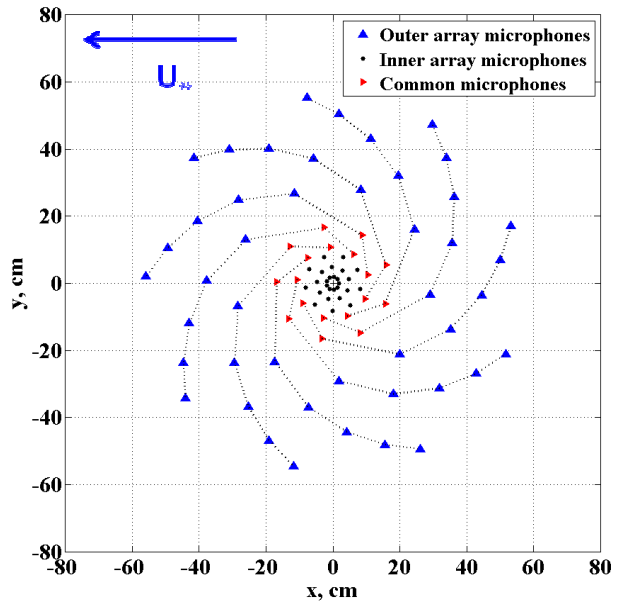

Figure 4. Microphone distribution of the LAMDA.
Calibration of the electret microphones is performed on an individual basis. Each microphone is flush-mounted side-byside with a 1/8"-diameter Brüel \& Kjaer Type 4138 pressurefield microphone at the end of a plane wave tube and excited by periodic random noise. Microphone sensitivities are then computed up to the tube cut-on frequency of $6.72 \mathrm{kHz}$. For this study, calibration of the LAMDA is performed using a group array calibration technique described in reference 13 .

To quantify the performance of the outer LAMDA at lower frequencies, the spatial selectivity of the array is determined by computing the 3-dB beamwidth as a function of frequency (Figure 5a). Note that the reference height of the "source" used in the computation is typical of that of a model mounted in the UFAFF test section. The point spread function (PSF) of the array and several array beamwidths denoted by contour lines at a frequency of $2 \mathrm{kHz}$ are shown in Figure $5(\mathrm{~b})$ to provide a qualitative representation of the array's performance.

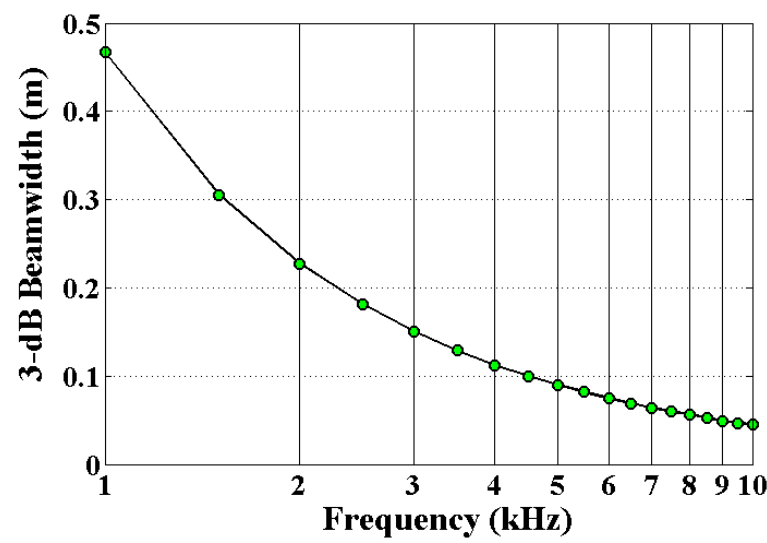

(a)

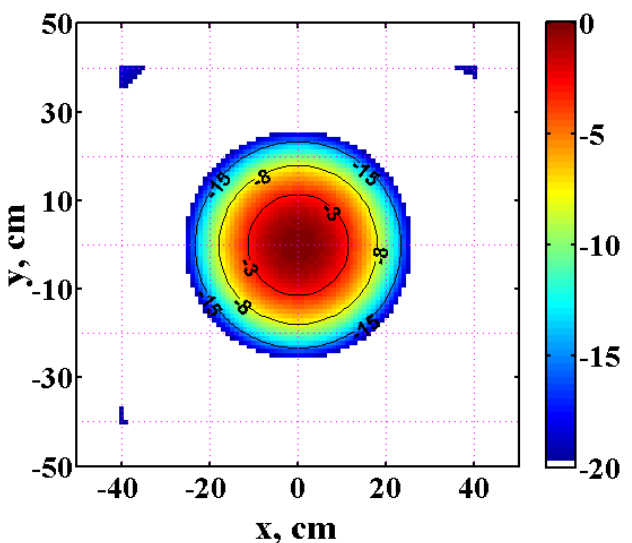

(b)

Figure 5. (a) 3-dB Beamwidth of outer LAMDA as a function of frequency, (b) PSF of outer LAMDA at a frequency of $F=2 \mathrm{kHz}$.

Beamforming is performed while the nose gear model is mounted within the UFAFF test section in both flyover and sideline orientations (Figure 6). Due to the size of the array plate, along with associated microphone circuitry and wiring, it is infeasible to rotate the array for both flyover and sideline views. Therefore, the landing gear model itself is rotated in the test section. While the flyover perspective from the LAMDA is

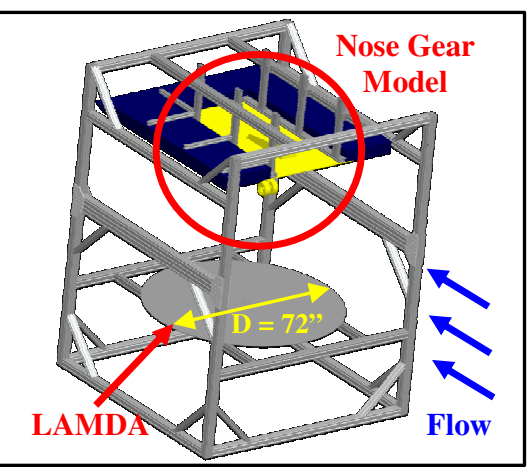

(a)

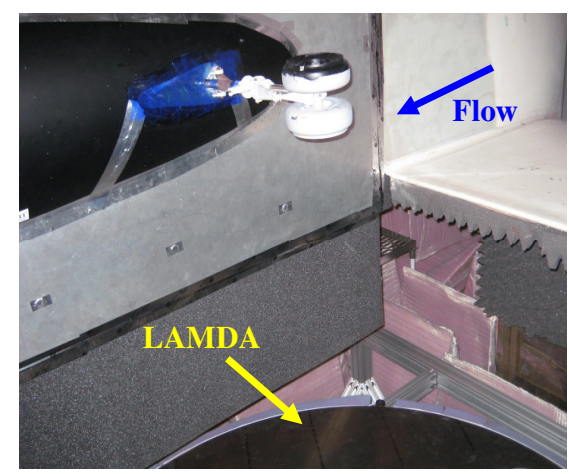

(b)

Figure 6. Test section configuration for beamforming in (a) flyover orientation, (b) sideline orientation.

airframe noise quantification, a sideline view of the landing gear for beamforming provides a better unobstructed view of the different potential noise sources. Only sideline beamforming plots are shown in this paper. 


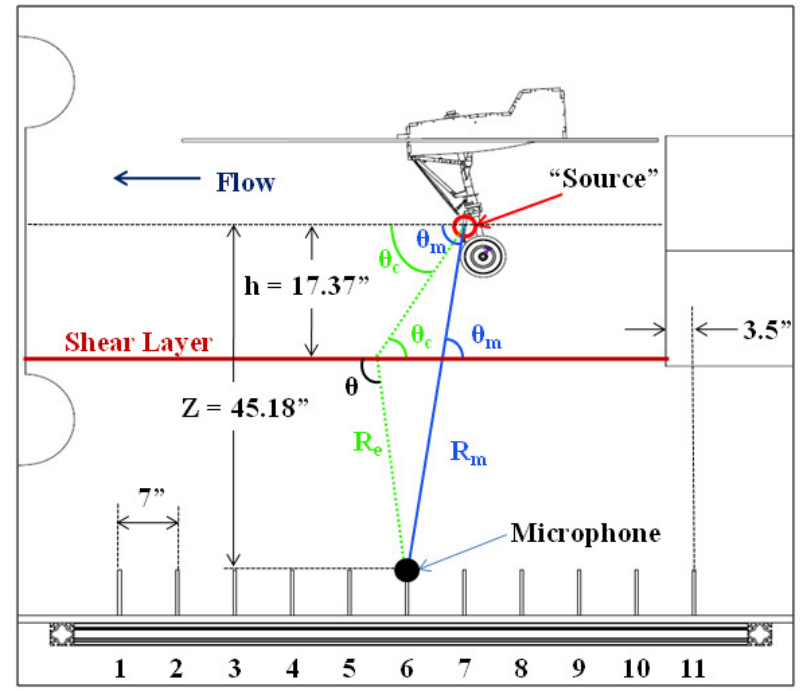

Figure 7. Schematic of linear array configuration for measuring flyover far field noise levels of the nose gear model with SLC Terminology.

A linear array of omni-directional free field microphones is used to acquire the far field noise level spectra along the length of the UFAFF test section. It consists of 11 of the same electret microphones used to populate the LAMDA. Each microphone is flush-mounted at the top of an aluminum tube measuring 6" $(0.152 \mathrm{~m})$, and the microphones are covered with a windscreen. The microphone tubes stem from an acoustically treated rail running along the bottom of the test section with a spacing of 7" $(0.178 \mathrm{~m})$ (see Figure 7). The total range of geometric radiation angles spanned by the linear array is approximately $47^{\circ} \leq$ $\theta_{\mathrm{m}} \leq 122^{\circ}$ as referenced from the upper torque arm of the model in the downstream direction. The linear array is situated along the length of the test section and positioned directly underneath the centerline of the gear model, with the plane of the microphones located approximately $28 "(0.711 \mathrm{~m})$ below the bottom inlet plane, or $42 "(1.07 \mathrm{~m})$ below the test section centerline (see Figure 7).

Since the UFAFF is an open-jet facility, a shear layer develops along the length of the test section. Sound that propagates from a model in the test section is refracted as it passes through this shear layer before it reaches the far field. Therefore, standard shear layer corrections (SLCs) are performed as outlined by Amiet ${ }^{14}$ for both the linear array and LAMDA. A schematic illustrating the SLC terminology as applied to the linear array is provided in Figure 7. The quantities $R_{m}$ and $\theta_{m}$ represent the measured source-to-microphone distances and radiation angles respectively, while $R_{e}$ and $\theta_{c}$ represent the effective source-to-microphone distances and corrected radiation angles, respectively. In addition, the quantities $h$ and $Z$ denote the source-to-shear layer distance and the distance from the source to the plane of the far field microphones, respectively. Note that in this figure, a region corresponding to the upper torque arm of the nose gear model is denoted as the nominal "source" location, since this location is found to be the primary source location via beamforming.

\section{Testing Conditions}

For the first phase of this study, steady and unsteady model surface pressure data are acquired. For this phase, data is acquired at two flow speeds corresponding to those run at the BART facility. The second phase consists of repeated unsteady pressure data runs, with acoustic measurements using the LAMDA and the linear array. For this phase, a third flow speed of $M=0.189$ is added to extract the appropriate scaling laws and to more closely correspond with actual landing speeds encountered by the Gulfstream G550 aircraft. Table 2 shows the test matrices of the two tunnel entry phases.

Table 2. Test matrix for first and second phases of nose gear model UFAFF entry.

\begin{tabular}{|c|r|r|r|}
\hline Orientation & \multicolumn{1}{|c|}{ DAQ } & Assembly Config. & Flow Speed (Mach \#) \\
\hline Flyover & Mean Cp & Fully-dressed, cavity open & $0.145,0.166$ \\
\hline & Kulites & Hydraulic lines OFF, cavity open & $0.145,0.166$ \\
\hline & & Hydraulic lines, lights OFF, cavity open & $0.145,0.166$ \\
\hline & & Hydraulic lines, lights, steering OFF, cavity closed & $0.145,0.166$ \\
\hline Flyover & Outer LAMDA & Fully-dressed, cavity open & $0.145,0.166,0.189$ \\
\hline & Linear Array & Hydraulic lines OFF, cavity open & $0.145,0.166$ \\
\hline & Kulites & Hydraulic lines, lights OFF, cavity open & $0.145,0.166$ \\
\hline & & Hydraulic lines, lights, steering OFF, cavity closed & $0.145,0.166,0.189$ \\
\hline Sideline & Outer LAMDA & Hydraulic lines, lights, steering OFF, cavity closed & $0.145,0.166,0.189$ \\
\hline & Kulites & Hydraulic lines, lights, steering OFF, cavity open & $0.145,0.166,0.189$ \\
\hline & & Fully-dressed, cavity open & $0.145,0.166,0.189$ \\
\hline
\end{tabular}




\section{Data Acquisition Parameters}

For unsteady data acquisition in the UFAFF, a National Instruments PXI-1045 chassis equipped with 17 NI PXI-4462 DAQ cards is used, yielding a total of 68 available channels. The sampling parameters for both Kulite and microphone data acquisition using the PXI are summarized in Table 3. Note that $\varepsilon_{\mathrm{r}}$ denotes the normalized autospectral random uncertainty. A useful feature of the PXI module is its ability to provide dc current excitation to the electret microphones. This feature is utilized for the microphone circuits used in the LAMDA and linear array, serving as a $4 \mathrm{~mA}$ dc current source for all microphone channels. The circuitry for the electret microphones consist of the microphone leads connected in parallel with a BNC connector and a 3.74-k $\Omega$ resistance to convert the $4 \mathrm{~mA}$ dc current into a voltage excitation. The circuitry resulted in an average electret microphone sensitivity of $30 \mathrm{mV} / \mathrm{Pa}$.

Table 3. Sampling parameters used for transducer data acquisition.

\begin{tabular}{|c|c|c|c|c|c|c|c|c|}
\hline Transducer & $\begin{array}{c}\text { Sampling } \\
\text { Rate (Hz) }\end{array}$ & Samples/block & $\begin{array}{c}\text { Window } \\
\text { Function }\end{array}$ & $\begin{array}{c}\text { Overlap } \\
(\boldsymbol{\%})\end{array}$ & $\mathbf{N}_{\text {blocks }}$ & $\begin{array}{c}\mathbf{N}_{\text {averages }} \\
\text { (effective) }\end{array}$ & $\begin{array}{c}\boldsymbol{\varepsilon}_{\mathbf{r}} \\
(\boldsymbol{\%})\end{array}$ & $\begin{array}{c}\text { Acqusition } \\
\text { Time (sec.) }\end{array}$ \\
\hline Kulite & 51,200 & 16384 & Hanning & 0 & 100 & 100 & 10 & 32 \\
\hline WM-61A & 65,536 & 2048 & Hanning & 75 & 320 & 664 & 3.9 & 10 \\
\hline
\end{tabular}

The following results compare aerodynamic and acoustic data between the principal benchmark landing gear assembly configurations: fullydressed cavity open (FDCO) and partiallydressed cavity closed (PDCC) model (Figure 8). In addition, a third model configuration is considered for the second phase of experiments, consisting of the model in a partially-

\section{Results}

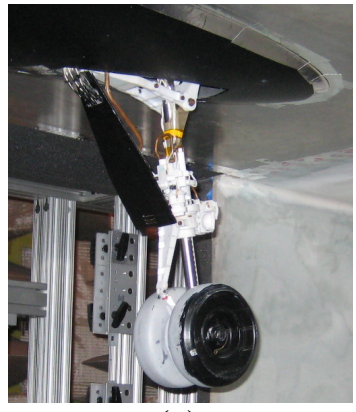

(a)

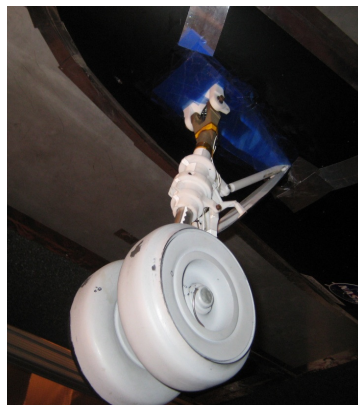

(b)

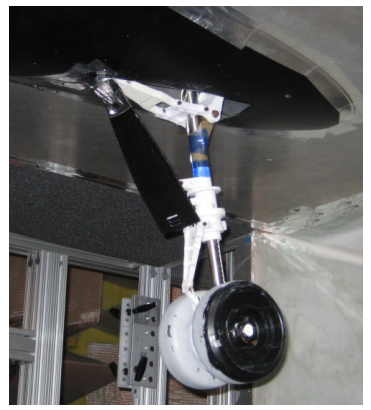

(c)
Figure 8. Model configurations: (a) fully-dressed cavity open (FDCO), (b) partially-dressed cavity closed (PDCC), and (c) partially-dressed cavity open (PDCO).

dressed cavity open (PDCO) configuration. This configuration combined with the cavity-closed case is important since it can potentially demonstrate the effect the cavity has on the overall acoustic signature of the nose gear model. Recall that the steering mechanism, hydraulic and electrical lines, and light system are the components removed for the partially-dressed model configurations (Figure 1, Table 2).

\section{A. Verification of Aerodynamic Trends}

A series of aerodynamic experiments performed on the nose gear model during the first entry into the UFAFF are used to compare the results with those from BART. Two regions of particular interest on the nose gear model in regard to mean pressure coefficient $\left(C_{p}\right)$ data are the door and the wheels. Figure 9 shows the nose gear door as well as a schematic of the door pressure tap distribution. Figures 10 and 11 compare the $C_{p}$ distributions on the gear door and starboard wheel obtained in the UFAFF and BART test runs, respectively. The testing conditions for this comparison are the PDCC case and a test section speed of $M=0.166\left(U_{\infty}=57.4 \mathrm{~m} / \mathrm{s}\right)$. As Figures 10 and 11 show, despite a nearly constant offset in the $C_{p}$ values, the trends of the data between the two tunnels are very similar.

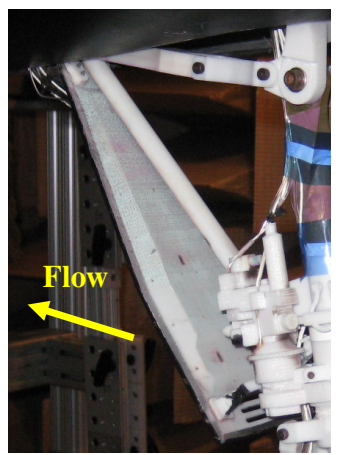

(a)

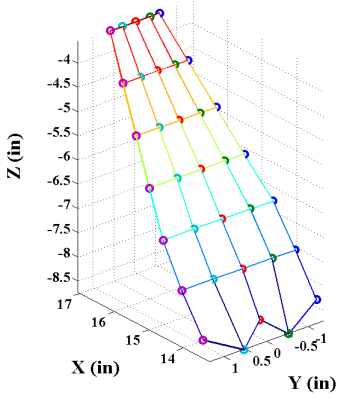

(b)
Figure 9. (a) Image of nose gear door, (b) visualization of door pressure tap distribution. 


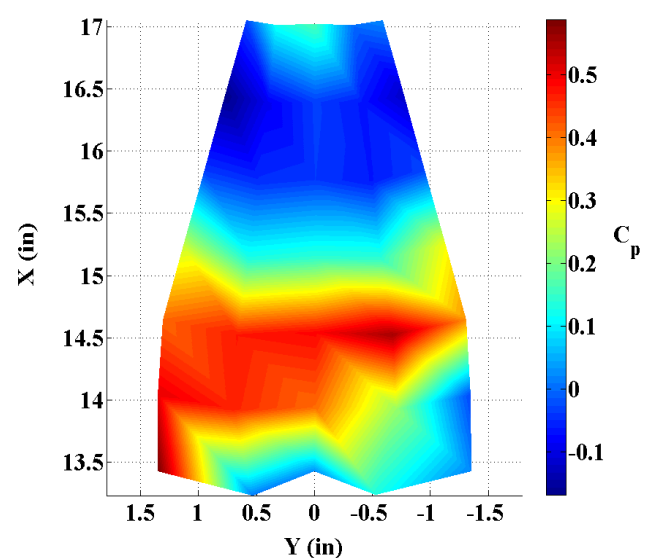

(a)

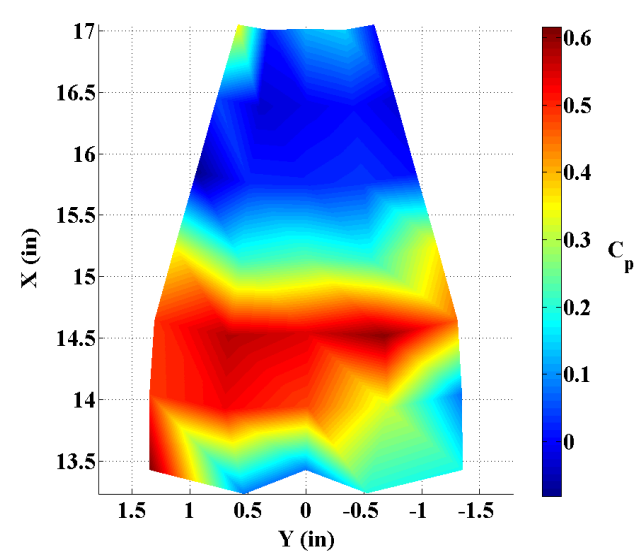

(b)

Figure 10. Comparison of gear door $C_{p}$ distribution between (a) BART, (b) UFAFF. (PDCC, $M=0.166)$

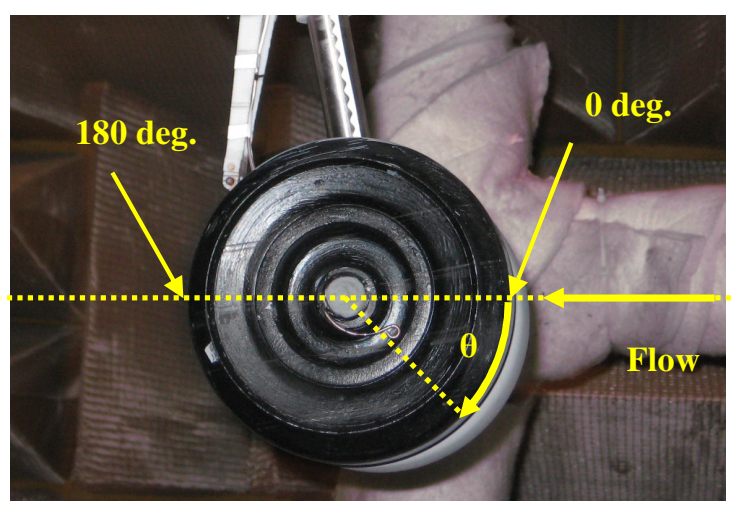

(a)

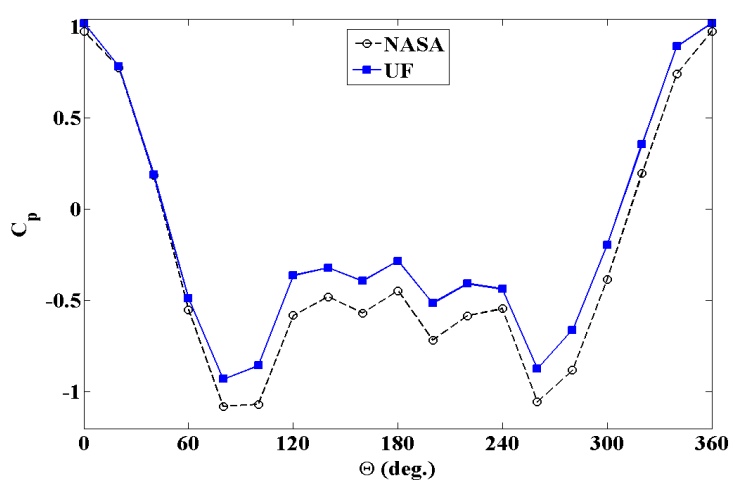

(b)

Figure 11. (a) Profile view of starboard wheel (angular coordinate system), (b) Angular $C_{p}$ distribution comparison between UFAFF and BART test runs. ( $P D C C, M=0.166$ )

The Kulite power spectral densities (PSDs) and root-meansquare (rms) $C_{p}$ values are also compared between the two facilities. Figure 13 shows two comparison plots of Kulite $C_{p, r m s}$ values, one for each benchmark model configuration at a tunnel flow speed of $M=0.166$. Note that Kulites 2, 6, and 12 are either not functional or not present on the model. As can be seen in Figure 13(a), there are some deviations for a few Kulite channels between BART and UFAFF. This is believed to be mainly due to different routing paths of the Kulite reference pressure lines along the model. This is especially apparent for Kulite \#15, which is located on the torque link mechanism (see Figure 12). While the other Kulite $C_{p, r m s}$ deviations between the two facilities are reduced for the PDCC case, the difference for Kulite \#15 actually increases from $\Delta C_{p, r m s}=0.03$ to 0.08 . Another feature worth noting is how in going from the FDCO to the PDCC geometry, the $C_{p}$ for this Kulite slightly decreases as recorded at BART versus an increase as recorded at the UFAFF. The next largest difference in $C_{p, r m s}$ occurs for Kulite \#5 in the FDCO test case, with $\Delta C_{p, r m s}=0.03$. This difference vanishes in the PDCC case.

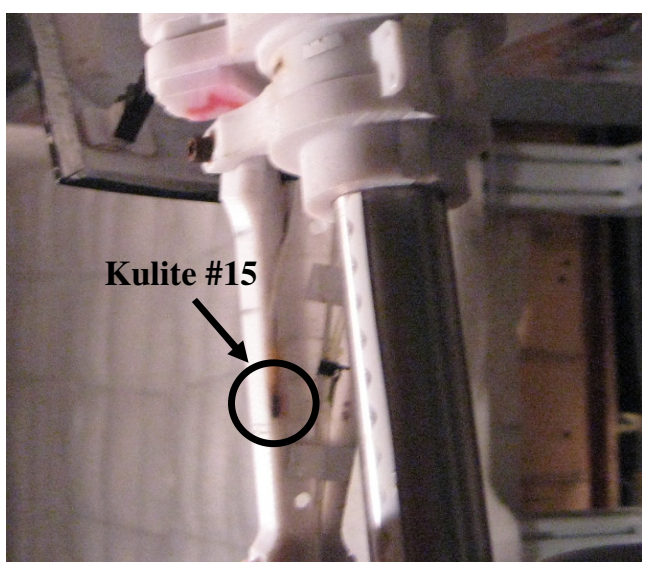

Figure 12. Location of upper torque arm Kulite relative to gear piston (shock strut). 


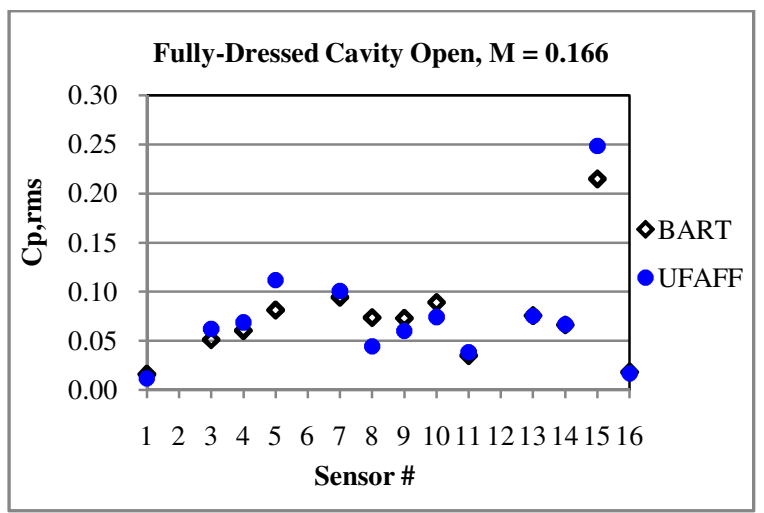

(a)

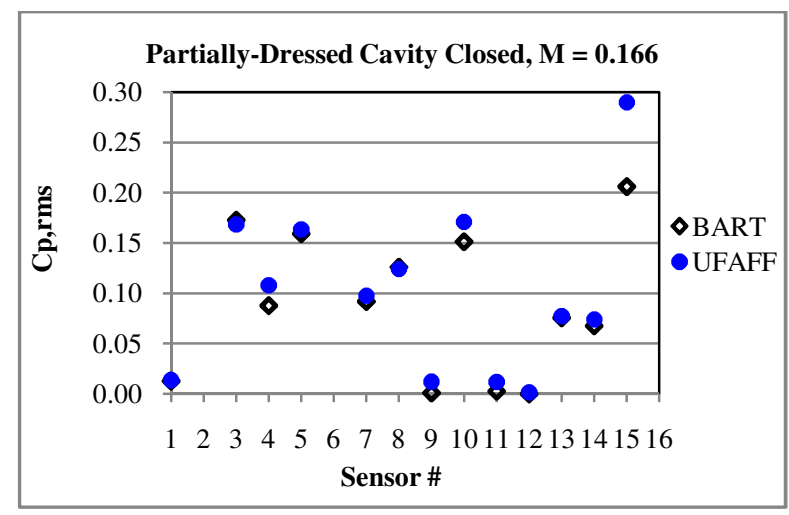

(b)

Figure 13. $C_{p, r m s}$ value comparisons for all functional Kulite channels between BART and UFAFF; (a) FDCO, (b) PDCC.

The differences between $C_{p, r m s}$ values for the Kulites between BART and UFAFF are further investigated by examining the PSDs for both benchmark configurations at a common speed of $M=0.166$. Figure 14 shows a comparison of four transducers between the two facilities for the PDCC case. Note that the Kulites shown in Figure 14 exhibit the highest $C_{P, r m s}$ values for this test case. For Figure 14(a)-(c), the general trend of the respective Kulite spectra are seen to be very similar between the two facilities. Figure 14(d), however, shows a considerable difference in the low- to mid-frequency range behavior of the transducer. The underlying cause of this discrepancy is currently unknown and is under investigation. It is important to note that none of the Kulite spectra reveal any spectral peaks indicative of vortex shedding phenomenon.

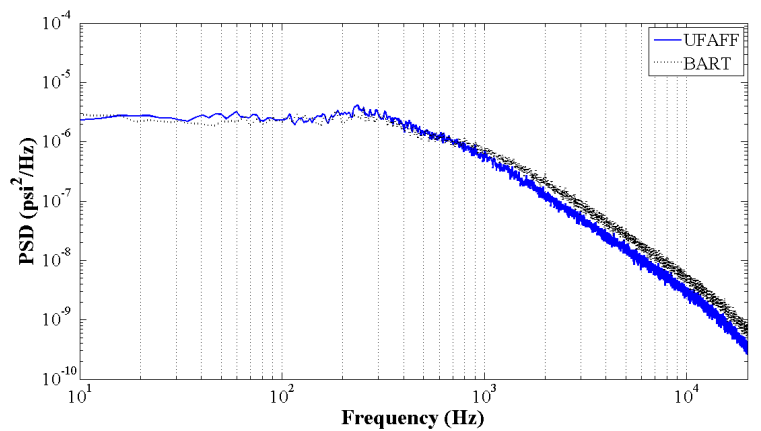

(a)

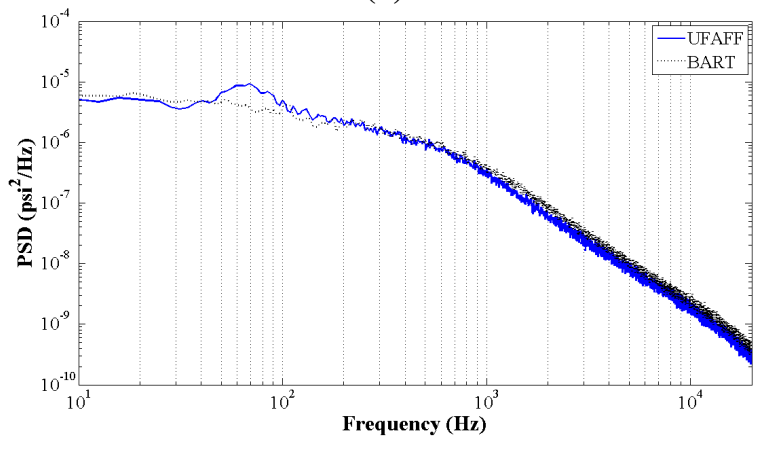

(c)

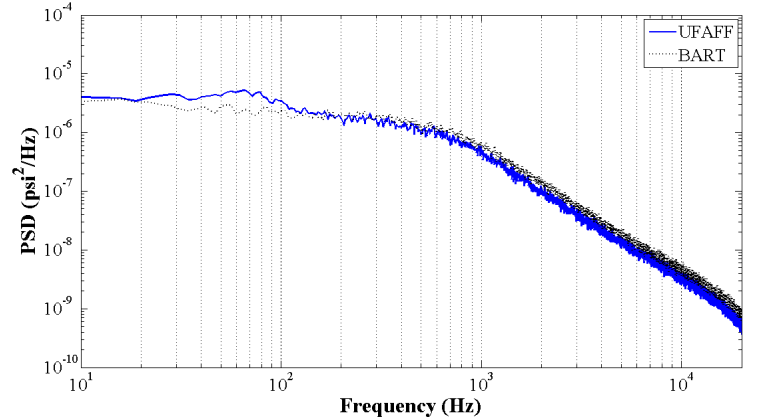

(b)

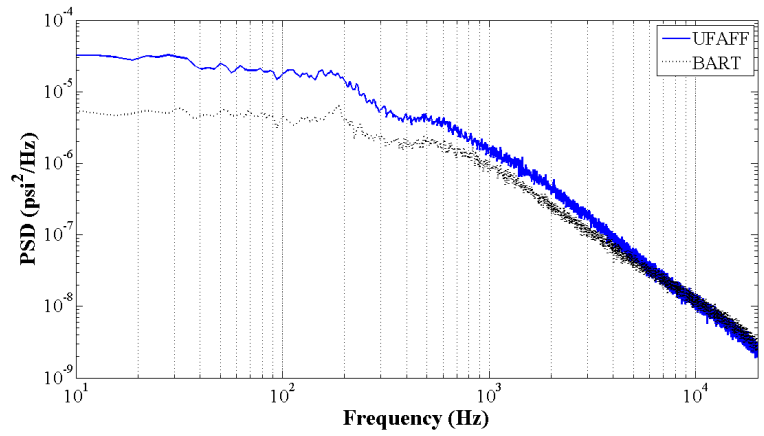

(d)

Figure 14. PSD comparison between UFAFF and BART facilities for (a) Kulite \#3, lower starboard door, (b) Kulite \#5, lower drag brace, (c) Kulite \#10, upper door, and (d) Kulite \#15, upper torque arm. (PDCC, $M=0.166$ ) 


\section{B. Aeroacoustic Analysis}

For the aeroacoustic testing, far field spectra are examined to isolate interesting spectral features of the nose gear model for the different model configurations. Beamforming is then performed at these frequencies to locate regions on the model that are most responsible for noise generation.

\section{B.1 Noise Source Localization}

As shown in Figure 7, linear array microphone \#7 is located almost directly below the upper torque arm Kulite. It is therefore the focus of the following analysis due to its "flyover" location. Both narrowband and $1 / 3^{\text {rd }}$ octave band weighted spectra computed from the raw microphone data for the three model configurations are shown in Figure 15. Spectra below $F=300 \mathrm{~Hz}$ are not presented since the distance from the source to the microphone is less than one acoustic wavelength. From Figure 15, the PDCC case exhibits higher sound pressure levels (SPLs) at lower frequencies $(300 \mathrm{~Hz}<F<1 \mathrm{kHz})$ and slightly lower SPLs at certain higher frequencies $(6 \mathrm{kHz}<F<10 \mathrm{kHz})$ when compared to the FDCO case. Even more noteworthy is the PDCO case, which is seen to exhibit power levels lower than the other configurations at all frequencies above $1 \mathrm{kHz}$. Due to the fact that closing the cavity suppresses the interactions between the cavity and the gear flow fields, the contributions of the removable gear components to the acoustic signature of the model is better assessed through direct comparison of the FDCO and PDCO configurations. Furthermore, since the gear components removed consist of geometries with multiple length scales, the measured SPL should decrease across a broad range of frequencies. Focusing attention on Figure $15(\mathrm{~b})$, the $1 / 3^{\text {rd }}$ octave spectra shows common tonal peaks at $F=1.25$ and $2.5 \mathrm{kHz}$ between the three configurations. From this behavior, it is initially assumed that the physical sources of these respective spectral peaks are

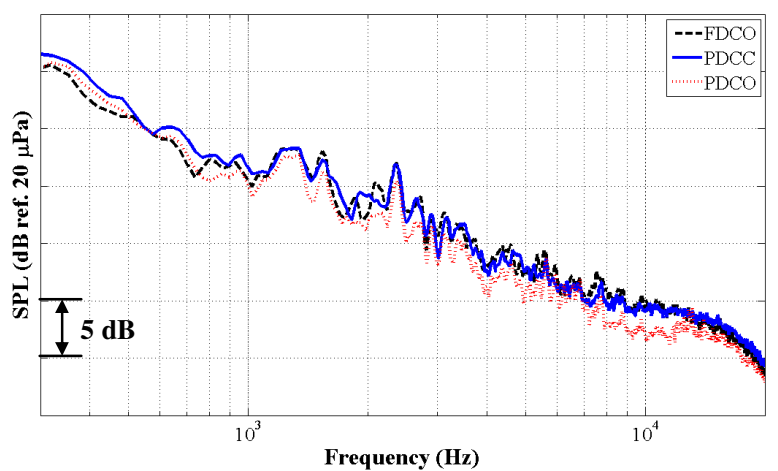

(a)

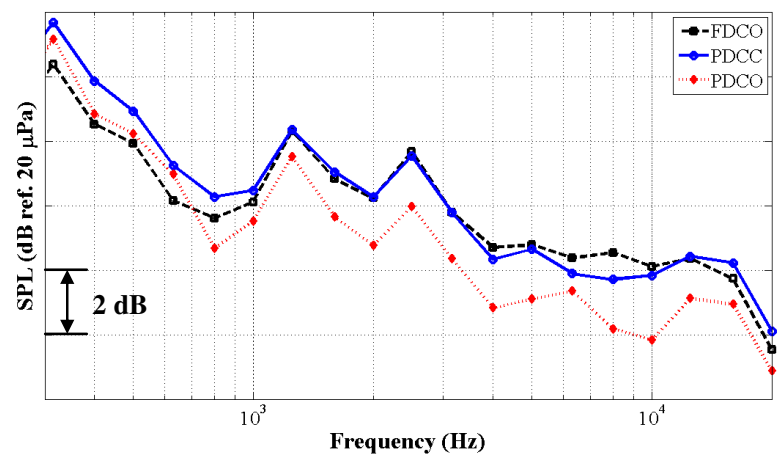

(b)

Figure 15. (a) Narrow-band and (b) $1 / 3^{\text {rd }}$ octave band spectra comparisons between model configurations at $\boldsymbol{M}=\mathbf{0 . 1 6 6}$. (Linear array microphone \#7)

common to the configurations. Sideline beamforming is then conducted at these tonal frequencies to a height corresponding to the central midplane of the model. Due to the higher resolution and reduced sidelobe levels associated with the Capon beamformers - specifically, the RCB - it is the primary algorithm used in this initial analysis. For example, Figure 16 shows a comparison of noise source localization plots between the DAS, SCB, and RCB algorithms at a frequency of $F=1.25 \mathrm{kHz}$ for the FDCO configuration at a flow speed of $M=0.166$. As the figure shows, the RCB algorithm outputs a much cleaner noise source localization plot, indicative of its higher resolution and robust nature. Note that all beamforming plots will be displayed in $1 / 3^{\text {rd }}$ octave bands. 


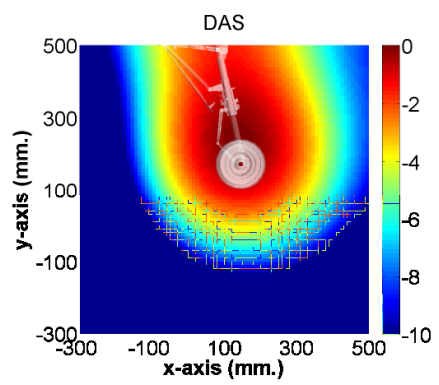

(a)

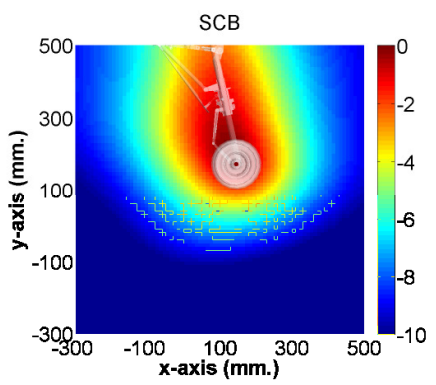

(b)

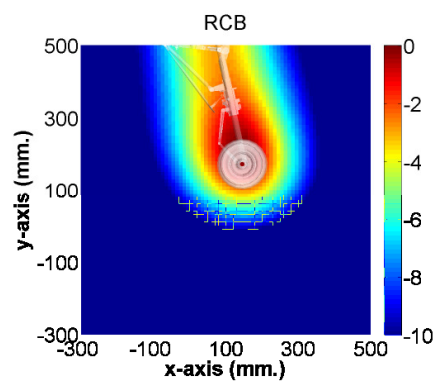

(c)

Figure 16. Sideline beamforming plots for FDCO case at a frequency of $F=1.25 \mathrm{kHz}$ using (a) DAS, (b) SCB, and (c) RCB algorithms. (Computed and plotted in $1 / 3^{\text {rd }}$ octave bands)

Beamforming comparisons are then conducted between the three configurations for $1 / 3^{\text {rd }}$ octave band frequencies of $F=1.25,2.5,4,5$, and $8 \mathrm{kHz}$. The three highest frequencies of 4,5 , and $8 \mathrm{kHz}$ are chosen to gauge the higher-frequency performance of the RCB algorithm and determine the primary differences between the model configurations in terms of dominant noise sources. Figure 17 shows a series of relative scale beamforming maps at the previously mentioned frequencies for the three model configurations at a flow speed of $M=0.166$. The beamforming maps are normalized relative to the respective peaks in each case.

From Figure 17(a)-(c), the general trend seems to be that the region of dominant noise generation corresponds to the wheels/axle at a frequency of $F=1.25 \mathrm{kHz}$. One interesting feature to note is how the source appears to become more localized in going from one configuration to the next. The trend is even seen to continue in comparing the cases of partially-dressed with closed versus open cavity configurations. The more localized source distribution for the PDCO case implies that the closed cavity can act as a reflective surface, effectively "smearing" the source distribution. It is also possible that the closed cavity may produce local flow accelerations and thus stronger acoustic sources. This effect is more evident in the FDCO case, possibly due to the presence of the additional gear components, such as the lights and steering mechanism. From Figure 1 it can be seen that these are fairly large in scale and can be noise source contributors within this frequency range. At a frequency of $F=2.5 \mathrm{kHz}$, the dominant source shifts away from the wheels and migrates upward, as can be seen in Figure 17 (d)-(f). For the FDCO case, the source distribution is smeared along the main strut region starting at the upper torque arm. This smearing effect appears to become mitigated with the removal of the complex components, as seen by cases (e) and (f). For these configurations, the torque link appears to be the dominant noise source contributor with some secondary contributions from the linkages near the cavity. The differences between the maps for the partially-dressed model geometry cases are less evident for the case of $F=2.5 \mathrm{kHz}$ when compared to those for $F=1.25 \mathrm{kHz}$. The only noticeable difference is a slight upstream shift of the apparent dominant source from the rear to the flow side of the torque link in going from the PDCC to the PDCO case.

Frequencies of $F=4$ and $5 \mathrm{kHz}$ show similar results with respect to one another. For the FDCO case $(\mathrm{g})$ and (j), the dominant source shifts to the front region of the main strut of the model corresponding to the light cluster and a simulated electrical line. In contrast, for the partially-dressed cases, the primary source remains the torque link region, with a slight upward shift toward the rear side of the main strut region at $F=5 \mathrm{kHz}$. At $F=8 \mathrm{kHz}$ the dominant noise sources are the light cluster for the FDCO case and the torque link for the partially-dressed cases. It is interesting to note how the beamforming maps identify the sources as more distributed with increasing frequency. This is consistent with the idea that noise sources become non-compact with increasing frequency, thereby becoming more directive. On the other hand, the progressive improvement in array resolution with increasing frequency tends to reveal individual noise sources while obscuring source directivity due to the large aperture of the array. These issues are difficult to sort out. In general, however, the torque link appears to be a common "hot spot" between the two partially-dressed model configurations. This is believed to be due to its interaction with the wake from the shock strut (piston). This trend was also identified by Dobrzynski et al. ${ }^{15}$ via CFD results for a preliminary re-design of the A340 Airbus nose landing gear. 


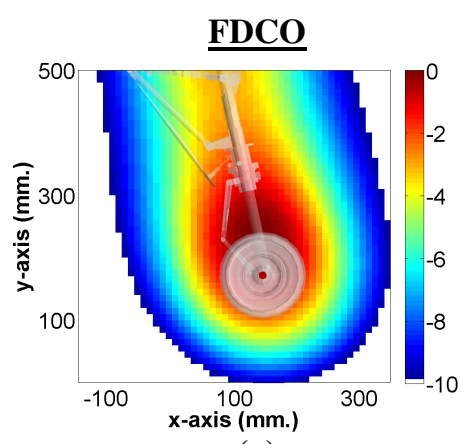

(a)

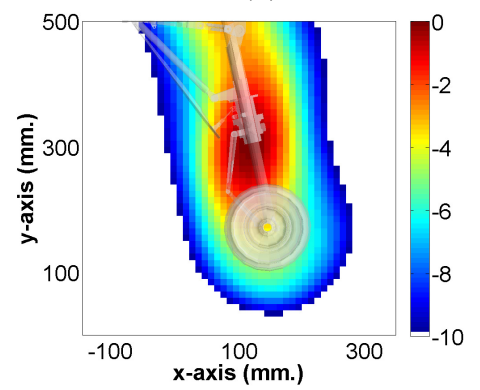

(d)

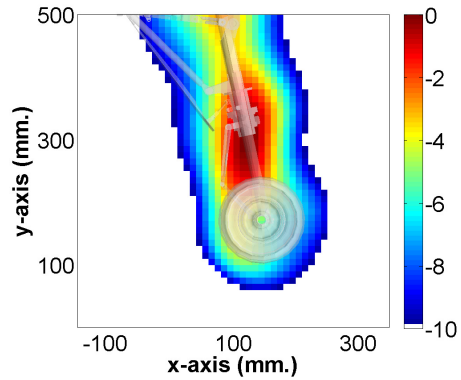

(g)

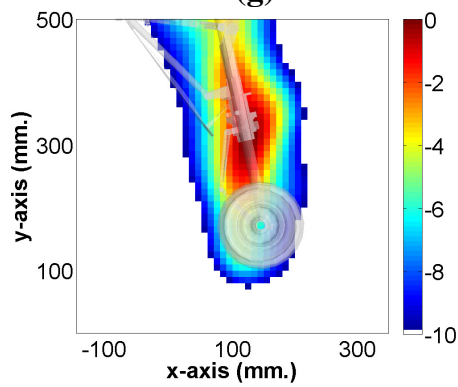

(j)

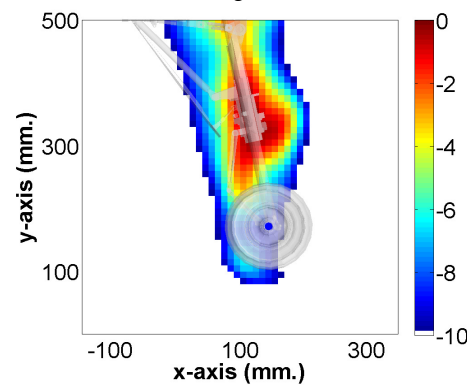

(m)

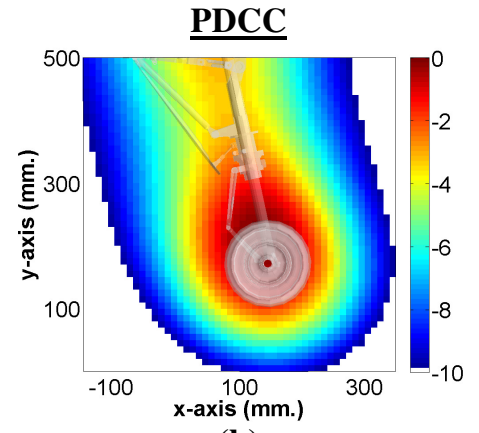

(b)

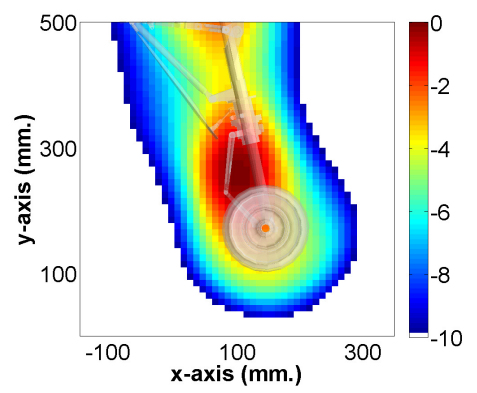

(e)

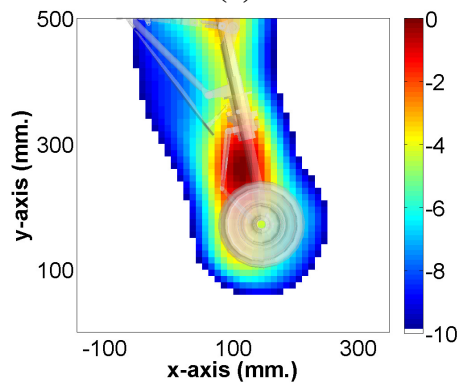

(h)

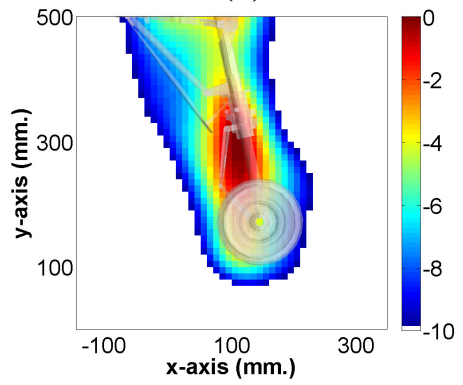

(k)

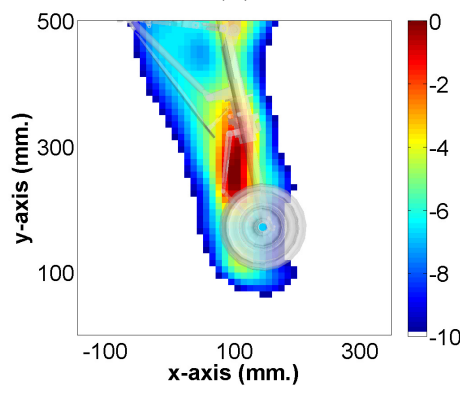

(n)

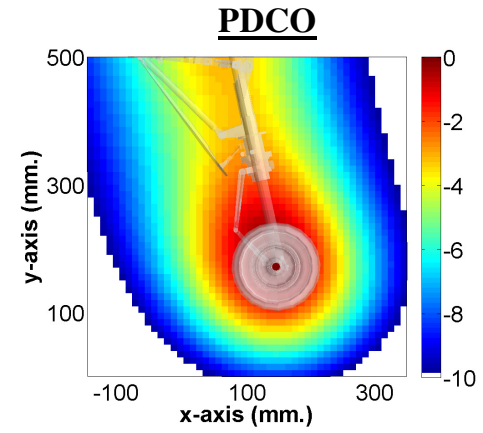

(c)

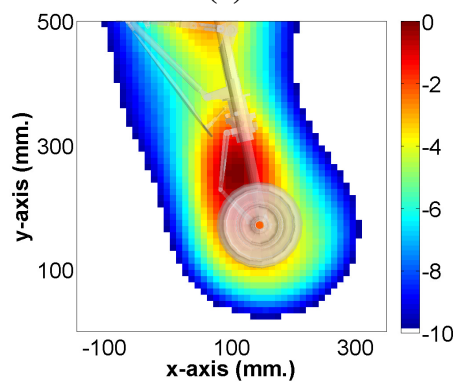

(f)

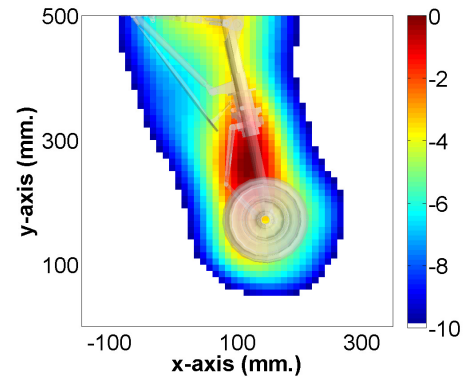

(i)

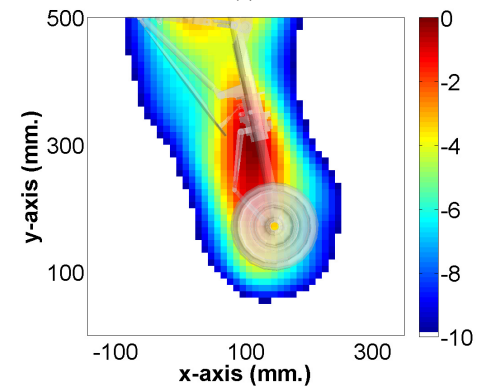

(I)

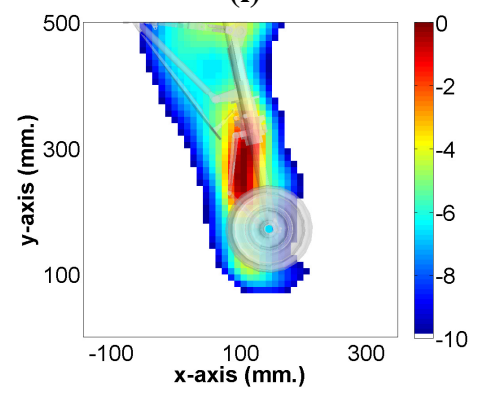

(o)

Figure 17. RCB noise source localization maps at frequencies (a)-(c) $F=1.25 \mathrm{kHz}$, (d)-(f) $F=2.5 \mathrm{kHz}$ (g)-(i) $F=4 \mathrm{kHz},(\mathrm{j})-(\mathrm{l}) F=5 \mathrm{kHz},(\mathrm{m})-(\mathrm{o}) F=8 \mathrm{kHz}$. 


\section{B.2 Scaling of Far Field Spectra}

Once the primary noise sources on the model are identified, the scaling of far field spectra as recorded by the linear array microphones is investigated. The autospectra of microphone 7 is discussed here due to its approximate flyover location relative to the model. A frequency range of interest of $1 \mathrm{kHz} \leq F \leq 16 \mathrm{kHz}$ is assumed based on geometrical scaling of those analyzed in reference 1. After applying the appropriate shear layer amplitude corrections for each microphone, a scaling corresponding to a $6^{\text {th }}$ power of velocity specifically, Mach number - is applied using the maximum tested flow speed of $M=0.189$ as a reference. The scaled autospectra in $\mathrm{dB}$ scale are computed as

$$
S P L_{\text {scaled }}(\mathrm{dB})=S P L_{\mathrm{C}}(\mathrm{dB})-10 \log \left(\frac{M}{0.189}\right)^{6},
$$

where $S P L_{\mathrm{C}}$ represents the sound pressure level after application of shear layer amplitude corrections. As can be seen in Figure 18, application of scaling using a $M^{6}$ power law collapses the data reasonably well for linear array microphone \#7 for all three model configurations with a slight deviation for the PDCO case in a frequency range of $5 \mathrm{kHz} \leq F \leq 10 \mathrm{kHz}$. The exact cause of this deviation is currently unknown. Very similar results are observed for the other microphones within the range of geometric radiation angles. Note that plots in the left column of Figure 18 represent the autospectra prior to scaling and those in the right column are those after scaling is performed. It is interesting to note that the spectra for all three configurations shift only in terms of amplitude with respect to flow speed and not frequency. This implies that the expected tonal behavior of the gear model is not dominant, since this would correspond to a frequency shift according to Strouhal scaling $f L / U$. The trends shown in this spectral analysis are consistent with full-scale flyover experiments of the Gulfstream G550 aircraft reported in reference 1.

\section{Conclusions \& Future Work}

The primary objectives of this study are to obtain a comprehensive aeroacoustic dataset for a nose landing

gear and to provide a clearer understanding of landing gear contributions to overall airframe noise of commercial aircraft during landing configurations. Comparison of model aerodynamic data between the UFAFF and BART facilities appear to yield consistent and repeatable results with the exception of the measured pressure field on the upper torque arm of the model which displayed higher PSD and $C_{p, r m s}$ levels at the UFAFF facility. Independent of the facility tested, the torque arm is seen to exhibit higher pressure levels than any other measured locations for all gear configurations.

Analysis of acoustic data taken in the UFAFF shows a slight decrease in SPLs at higher frequencies in going from a fully-dressed to a partially-dressed cavity open model configuration as well as a noticeable difference in the sideline noise source localization maps. In contrast, flyover beamforming maps were found to be noninformative in identifying dominant noise sources. For the fully-dressed model, the dominant noise sources appear to be the wheels $(F=1.25 \mathrm{kHz})$, upper torque $\operatorname{arm}(\mathrm{F}=2.5 \mathrm{kHz})$, and light cluster $(4 \mathrm{kHz} \leq F \leq 8 \mathrm{kHz})$, Removal of the hydraulic lines, light cluster, and steering mechanism from the gear main strut yielded a shift in noise source "hot spots" from the lights to the upper torque arm and rear section of the main strut over a frequency range of $4 \mathrm{kHz} \leq F \leq 8 \mathrm{kHz}$. Overall, the torque arm region is an important noise contributor for all configurations. In addition, flyover far field microphone spectra scale with the $6^{\text {th }}$ power of velocity and do not exhibit Strouhal scaling behavior.

As a continuation of this effort, advanced beamforming algorithms such as SC-DAMAS and CMF will be implemented in an attempt to achieve noise source localizations with higher resolution. Coherence-based methods ${ }^{16}$ will also be utilized to aid in the removal of uncorrelated noise from far field spectra. Finally, laser Doppler velocimetry (LDV) will be used to measure and analyze the turbulent local flow velocity fields around and in between the complex gear components in order to document the state of the local flow fields. LDV is better suited than Particle Image Velocimetry (PIV) to gain access to regions that are difficult to illuminate with a laser light sheet. 


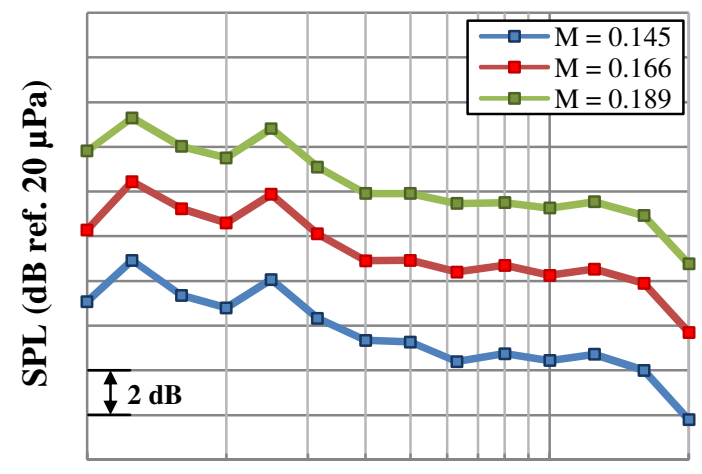

$1 . \mathrm{E}+03$

Frequency $(\mathbf{H z})$

(a)

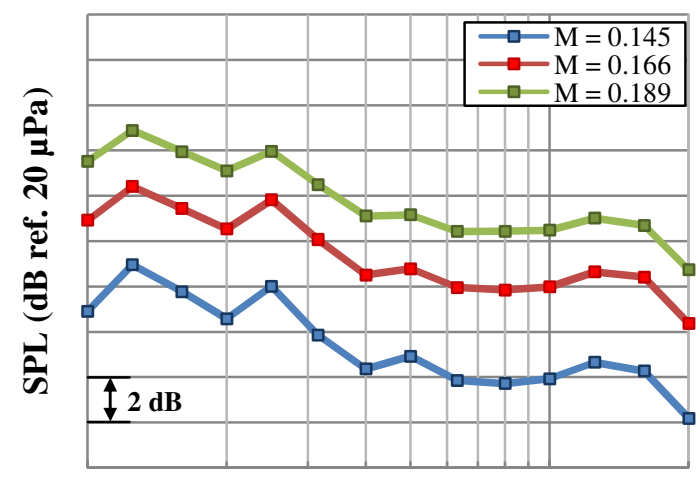

$1 . \mathrm{E}+03$

Frequency $(\mathrm{Hz})$

(c)

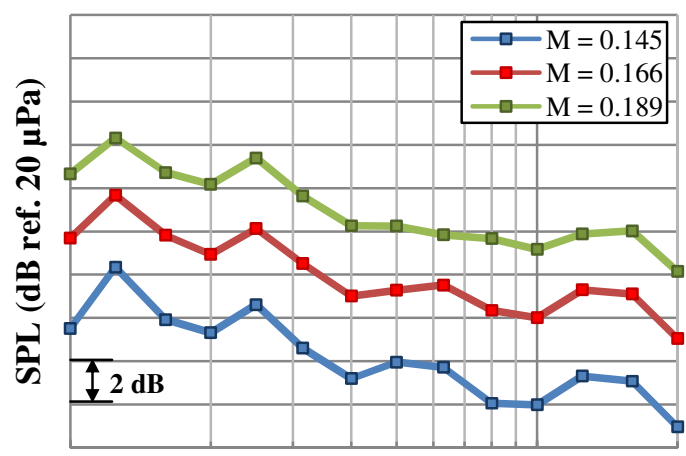

1.E+03 Frequency $(\mathbf{H z})^{1 . \mathrm{E}+04}$

(e)

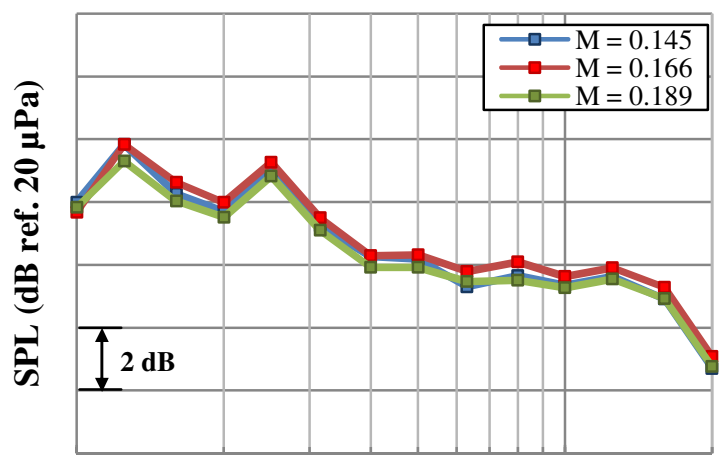

$1 . \mathrm{E}+03$ Frequency $(\mathrm{Hz})$

(b)

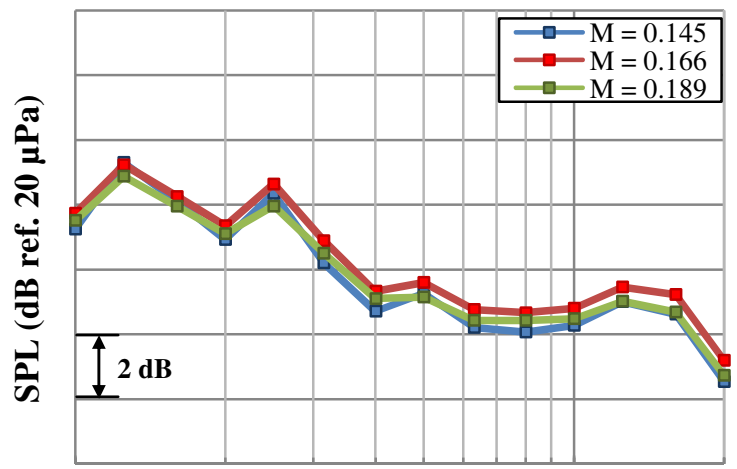

1.E+03

Frequency $(\mathrm{Hz})$

(d)

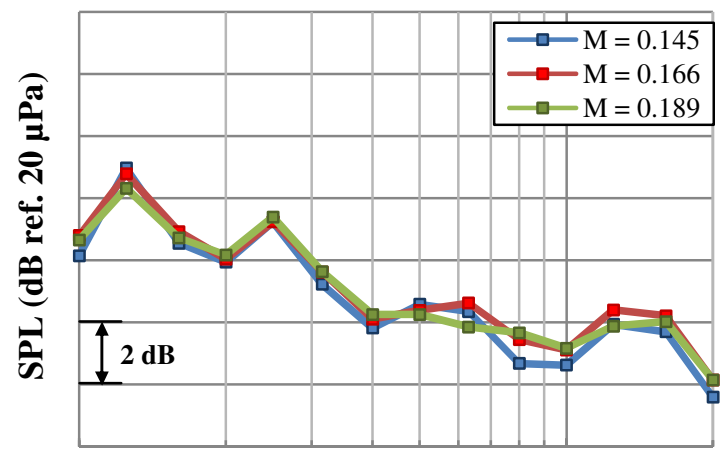

1.E+03

Frequency (Hz) ${ }^{1 . \mathrm{E}+04}$

(f)

Figure 18. Dependence of far field autospectra on Mach number plotted in $1 / 3^{\text {rd }}$ octave bands: (a)-(b) FDCO, (c)-(d) PDCC, (e)-(f) PDCO. Left column: raw autospectra. Right column: scaled spectra using $\mathbf{M}^{6}$ power law. (Linear array microphone \#7)

\section{Acknowledgments}

The first four authors would like to acknowledge Gulfstream Aerospace Corporation and the Florida Center for Advanced Aero-Propulsion (FCAAP) for their financial support. These authors would also like to acknowledge the NASA Langley Research Center for providing the landing gear model used in this study. N. S. Zawodny thanks Donald Day of NASA Langley for lending his technical expertise in configuring the landing 
gear model for testing within the UFAFF, Christopher Bahr of the University of Florida for his assistance on data acquisition and processing, and Adam Edstrand, Alberto Gordon, Tom Kennedy, and Christopher Pergola of the University of Florida for their assistance on model installation and wind tunnel testing.

\section{References}

\footnotetext{
${ }^{1}$ Khorrami, M. R., Lockard, D. P., Humphreys, W. M., Jr., Choudhari, M. M., and Van de Ven, T., "Preliminary Analysis of Acoustic Measurements from the NASA-Gulfstream Airframe Noise Flight Test," AIAA Paper 2008-2814, 14 ${ }^{\text {th }}$ AIAA/CEAS Aeroacoustics Conference, Vancouver, Canada, May 5-7, 2008.

${ }^{2}$ Guo, Y., "A Statistical Model for Landing Gear Noise Prediction," AIAA Paper 2003-3227, $9^{\text {th }}$ AIAA/CEAS Aeroacoustics Conference, Hilton Head, SC, May 12-14, 2003.

${ }^{3}$ Guo, Y., Yamamoto, K. J., and Stoker, R. W., "Experimental Study on Aircraft Landing Gear Noise," Journal of Aircraft, Vol. 43, No. 2, pp. 306-317, 2006.

${ }^{4}$ Hutcheson, F. V., and Brooks, T. F., "Noise Reduction from Single and Multiple Rod Configurations," AIAA Paper 2006-2629, 12 $2^{\text {th }}$ AIAA/CEAS Aeroacoustics Conference, Cambridge, MA, May 8-10, 2006.

${ }^{5}$ Arnold, D., "A MEMS-Based Directional Acoustic Array for Aeroacoustic Measurements," M.S. Thesis, Department of Electrical and Computer Engineering, University of Florida, Gainesville, FL, 2001.

${ }^{6}$ Capon, J., "High Resolution Frequency-Wavenumber Spectrum Analysis," Proceedings of the IEEE, 57:1408-1418, August 1969.

${ }^{7}$ Brooks, T. F., and Humphreys, W. M., "A Deconvolution Approach for the Mapping of Acoustic Sources (DAMAS) Determined from Phased Microphone Arrays," Journal of Sound and Vibration, Vol. 294, pp. 856-879, 2006.

${ }^{8}$ Yardibi, T., Li, J., Stoica, P., and Cattafesta, L. N., III, "Sparsity Constrained Deconvolution Approaches for Acoustic Source Mapping," Journal of the Acoustical Society of America, Vol. 123, No. 5, pp. 2631-2642, 2008.

${ }^{9}$ Sijtsma, P., "CLEAN Based on Spatial Source Coherence," AIAA Paper 2007-3436, $13^{\text {th }}$ AIAA/CEAS Aeroacoustics Conference, Rome, Italy, May 21-23, 2007.

${ }^{10}$ Neuhart, D.H., Khorrami, M.R., and Choudhari, M.M., "Aerodynamics of a Gulfstream G550 Nose Landing Gear Model," AIAA Paper 2009-3152, Miami, May 11-13, 2009.

${ }^{11}$ Sellers, W. L., III, and Kjelgaard, S. O., "The Basic Aerodynamics Research Tunnel - A Facility Dedicated to Code Validation," AIAA Paper 1988-1997, Hampton, VA, 1988.

${ }^{12}$ Underbrink, J. R., M.S. Thesis, "Practical Considerations in Array Design for Passive Broad-Band Source Mapping Applications," The Pennsylvania State University, State College, PA, 1995.

${ }^{13}$ Dougherty, R. P., "Beamforming in Acoustic Testing," Aeroacoustic Measurements, Edited by T. J. Mueller, Springer, pp. 63-97, 2002.

${ }^{14}$ Amiet, R. K., "Refraction of Sound by a Shear Layer," Journal of Sound and Vibration, Vol. 58, No. 3, pp. 467-482, 1978.

${ }^{15}$ Dobrzynski, W. M., Schoning, B., Chow, L. C., Wood, C., Smith, M., and Seror, C., "Design and Testing of Low Noise Landing Gears," AIAA Paper 2005-3008, $11^{\text {th }}$ AIAA/CEAS Aeroacoustics Conference, Monterey, CA, May 23-25, 2005.

${ }^{16}$ Bahr, C., Yardibi, T., Liu, F., and Cattafesta, L., "An Analysis of Different Measurement Techniques for Airfoil Trailing

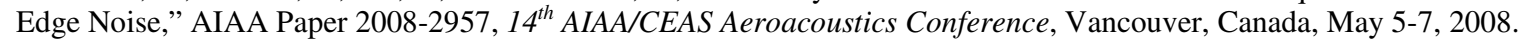

